\title{
EDITORIAL
}

\section{Editorial 2021 greetings}

\section{Fabrice Duparc ${ }^{1} \cdot$ Bruno Grignon $^{2}$}

Published online: 5 January 2021

(c) The Author(s), under exclusive licence to Springer-Verlag France SAS part of Springer Nature 2021

Dear anatomists and clinicians,

We could not imagine, 1 year ago, that 2020 would be so difficult in our universities and hospitals, due to an unexpected pandemic.

Paradoxically, despite so serious difficulties for researching and teaching, our editorial activity developed and reached a never seen level before, with more than 1000 submissions received from 68 countries. The cancelled meetings and congresses did not allow oral communications of the studies, and a greater number of authors had obviously more time for concluding their studies and editing their manuscripts.

From a practical point of view, Surgical and Radiologic Anatomy became a monthly journal in 2017, and 12 issues per year will continue to gather the previously online published articles, but the number of articles per issue still needs to be increased.

Special thanks are given to the Associate Editors and Reviewers for their huge work that could make possible this great evolution of publishing in the fields of anatomical sciences, clinical anatomy and education.

We wish you all the best for 2021 !

F Duparc and B Grignon.

Publisher's Note Springer Nature remains neutral with regard to jurisdictional claims in published maps and institutional affiliations.

Fabrice Duparc

fabrice.duparc@univ-rouen.fr

1 Laboratory of Anatomy, Faculty of Medicine, Rouen-

Normandy University, 22 boulevard Gambetta,

76183 Rouen, France

2 Department of Anatomy, University of Lorraine, Avenue de la Forêt de Haye, 54505 Vandoeuvre-Les-Nancy, France 